\section{A FOREIGN BODY IN THE LEFT BRONCHUS OF A CHILD EXPELLED THROUGH A TRACHEOTOMY WOUND ON THE FIFTEENTH DAY AFTER INHALATION.}

BY H. S. CLOGG, M.S. LoND., F.R.C.S. ENG., ASSTSTANT SURGEON TO CHARING CROSS HOSPITAL; SENIOR SURGEON TO THE EVELINA HOSPITAL FOR SICK CHILDREN.

A LITTLE boy, aged one year and nine months, was seen by his parents on August 3rd to have a mouthful of chicken corn. He was told to spit this out, which he did, but not without a severe fit of coughing. From that date to the 7 th he had repeated attacks of conghing without any very evident distress in breathing. In the intervals between these attacks he seemed perfectly well and was running about as usual. On the 7 th he was taken home, a railway journey of 25 miles. On the morning of the 8 th the child had a severe convalsive coughing fit with great respiratory distress and the breathing ceased for a few moments. Artificial respiration was performed. Natural breathing was restored and the coughing and respiratory distress gradually passed off. On the evening of the same day the child had a similar attack. Again on the evening of the 9 th he had an attack of marked dyspucea ; the temperature was normal and the respirations were 76 ; there was deficient entry of air into the left lung. By observing the effect of position it was noticed that the child breathed the easiest when lying flat on his back. In this position it was thought that air entered the left upper lobe. The dyspnœa lasted for about two hours; the child slept all night; during sleep the respirations were 44 . On the 10th there were two attacks of dyspncea and coughing, each lasting about two hours; these were not so severe as the former attacks had been. There was one dyspnceal attack on the following day and the temperature rose to $101 \cdot 6^{\circ} \mathrm{F}$. but it fell to normal again in three hours. This was the only time the temperature was raised. On the 12th there were no paroxysms of dyspncea, but the respirations were from 50 to 60 , while the temperature was normal and the pulse ranged from 120 to 130 . The child seemed bright and playful. On the 13 th he was brought up to London, a distance of 200 miles. There had not been any attack of dyspnoea since the 11th; the respirations varied between 40 and 50 and the pulse from 120 to 130 . The child had been kept flat on his back since this was found to be the position easiest for breathing. Since the evening of the $9 \mathrm{th}$ the condition of the left lung had practically not changed, the percussion note was quite flat and the breath sounds were inaudible over the lower and very faint over the upper lobe; marked recession of the intercostal spaces was present. At times moist sounds were heard over the lung, and the child during the fits of coughing seemed to expectorate mucus into the mouth which was promptly swallowed. It seemed pretty clear that a piece of corn had found its way into the left bronchus and was obstructing it, and probably more the lower than the upper division of the bronchus.

Under chloroform anæesthesia the trachea was opened. This was incised as low as possible in the neck and a long opening was made so as to get as near to the bifurcation as possible by this route. An enlarged thymus considerably added to the difficulties of exposure; this extended into the root of the neck and obscured very much the tracheal opening. The trachea was held widely open with retractors and the thymus held down and instruments of various sizes and shapes were passed down the wind-pipe. Probes, curved wire, and various forceps were all tried without avail. The right bronchus could be entered but not the left. In spite of a thorough trial, lasting nearly an hour, the foreign body could not be extracted. The child was allowed to come nearly round from the anæs. thetic, coughing was excited, and various positions were tried, but all were useless. A tracheotomy tube was inserted. On account of the large hole in the trachea and the enlarged thymus gland a silver tube could not be used, since it was not long enough and was jerked out at once by the elevation of the thymus during respiration; a long rubber tube was therefore employed. On the same evening the respirations rose to 72 and the temperature to $102^{\circ}$, and the child became very ill. During the night a severe dyspnoeal attack occurrel which was relieved by the inbalation of oxygen. On the following day it was noticed that there was deficient entry of air into the lower lobe of the right lung and an area of bronchial breathing was present at the apex of this lobe; numerous moist sounds were heard over the right chest and there was recession of the lower intercostal spaces. During the following two days the condition remained much about the same. The physical signs in the chest were unaltered; at no time could it be certain that any more air was entering the left lung. The temperature ranged from $99^{\circ}$ to $101.6^{\circ}$, the respirations from 60 to 72 , and more urgent dyspncea occurred at times. The tube was left in and quantities of mucus were expelled through it. The physical signs suggested that the left bronchus was more or less completely occluded and the right one also to some extent; the foreign body, therefore, was probably lying at the bifurcation of the trachea. On the third day after the tracheotomy the tube was removed and a further attempt (without anæsthesia) was made to remove the foreign body. This was unsuccessful. A silver tube was now inserted. The process was repeated on the following day and again on the next day, when after a violent fit of coughing and dyspncea which lasted for some minutes, and during which the child seemed nearly dead, the body was seen in the depths of the wound and was removed. During this paroxysm of coughing and dyspncea it seemed pretty certain that the body must have changed its position and must have lain in the trachea; various forceps were passed down but it could not be grasped, nor even felt, not even in this short length of trachea. The body was a piece of maize swollen to two or three times its natural size; on drying it, it soon shrank down to its normal size and was absolutely unaltered; it was not even split. The tracheotomy tube was at once left out and the wound was allowed to close, which it speedily did, becoming merely superficial in six days. On examining the chest a few hours after the body had been expelled a marked change was noted to have taken place. Over the whole of the left lung and the lower part of the right lung there were intense bronchial breathing and numerous moist sounds. Day by day the breathing became less bronchial and more and more normal and the râles lessened; the last portion to clear was that near the root of the lung. During the first few days considerable quantities of mucus were expelled from the tracheotomy wound. This lessened and ceased in six days. The lungs did not return to their normal condition, as judged by physical signs, until eight days after the expulsion of the body. During the whole of this time the temperature was normal. The respirations for the first two days remained frequent at from 50 to 60 ; this frequency gradually diminished as the signs in the chest disappeared. Harley-street, W.

\section{ON THE OCCASIONAL NECESSITY OF DRAINAGE OF THE UTERUS IN PUERPERAL INFECTION.}

BY A. A. WARDEN, M.D. GLASG. \& PARIS PHYSICIAN TO THE HERTFORD BRITISH HOSPITAL, PARIS.

WHEN a mere practitioner ventures into print upon subject connected with the work of specialists he must indeed both excuse and justify his action. The details of the following case, interesting and instructive to me, may contain nothing new or of infrequent occurrence in the larger experience of acconcheurs but may, un the other hand, corroborate conclusions that are already generally admitted.

Fven specialists and consultants will not, I believe, contest one advantage enjoyed over them by the general practitioner. His constant contact with the patient enables him to detect changes, to see cause and effect in treatment, and to realise the meaning of certain phenomena in a measure that cannot be appreciated by the brief examination, however thorough, of the physician called in consultation. It has often seemed to me that the consultant is at a great disadvantage, both as regards his ability to help the patient and as regards his interest in the subsequent course of the ailment, just because his examination of the patient must be so brief and so isolated. He cannot see for himself whether his treatment is properly followed or results in advantage to the patient: he sometimes does not even know if his diagnosis of a difficult case has been correct.

The case I would now refer to may be summed up as one 
of paerperal infection due to retention of lochia, unrelieved by carettage and intra-uterine douching, cured by aterine drainage. I may add that I had during the course of the illness the advantage of consultation with the late Professor Budin who took a very grave view and did not hesitate to describe it as la grande infeotion, that is to say, generalised puerperal infection. The accouchement-of a second childtook place simply and normally on June 18th at what may be termed the customary hour of $3 \mathrm{~A} . \mathrm{M}$. Following my usual practice I had entirely avoided vaginal examination from the onset of labour, the progress of which $I$ had followed by abdominal palpation. For three days the patient's condition was excellent. (Looking back it seems probable, however, that at this stage an abnormal diminution of the lochia might have been noticed or at least suspected.) On the fourth day there was a rise of temperature to $102^{\circ} \mathrm{F}$. with pain low down in the abdomen on the right side. As the bowels had not moved since the confinement an enema was given with good result and for 36 hours the temperature remained normal. On the evening of the sixth day there was a rise to $101^{\circ}$ and on the next day, during my absence, my friend, Dr. C. K. Au tin, saw the patient, the temperature being $103^{\circ} 6^{\circ}$ and the pulse 110 . He gave an intra-uterine douche by which a large amount-about half a litre-of brown turbid fluid was washed out. This in no way relieved the patient, at least in so far as her comfort was concerned, as it was immediately followed by a violent rigor, the temperature remaining: high and the pulse rapid. On the next morning I repeated the intra-uterine douche, similariy washing out much turbid fluid. Within half an hour the temperature rose from $100 \cdot 6^{\circ}$ to $104 \cdot 6^{\circ}$, the pulse to 128 , and an alarming and prolonged rigor occurred. Professor Budin saw the patient at 2 P.M., soon after a third intra-uterine douche had been given, and during his visit the third rigor took place. Professor Budin's prognosis was of the gloomiest, and he expressed the opinion that unless the uterus were at once curetted death would probably take place. At 6 P.M. the patient was anæesthetised and the uterus thoroughly cleaned out with the écouvillon or quillmop-the instrument preferred to the steel curette by both Budin and Doleris for this purpose. ${ }^{1}$ The curette brought no placental débris away and there was no evidence of sloughing or desp infection of the uterine mucous membrane. The cavity of the uterus was packed with iodoform gauze. That night the situation seemed saved, the condition of the patient was excellent, the temperature normal, and the pulse 84 . On the following morning, by Professor Budin's directions and by his assistant, the gauze was removed and an intra-uterine douche was given ( 40 grammes of tincture of iodine and 6 grammes of potassium iodide to the litre), the temperature being normal and the pulse 74 . At 6 P.M. a second intrauterine douche was given, and three-quarters of an hour later tout était à recommencer-viz., temperature $102 \cdot 6^{\circ}$, violent rigor, and rapid pulse. I therefore decided once more to pack the uterus and thereby prevent the accumulation of fluid. This dressing - namely, an intra-uterine douche followed by packing with iodoform gauze-I repeated the next morning and for 48 hours had the pleasure of seeing my patient maintain a uniformly good condition with normal pulse and temperature, the milk having, however, completely left the breasts, showing the intensity of the general infection. On the following day I replaced the gauze packing by a long intra-uterine glass drain and a vaginal gauze plug, the pulse being 72. In deference to the opinion of my consultants, who strongly recommended intra-uterine douching and equally strongly deprecated drainage of the uterus as risking contamination from the vagina and from without, I now-on the eleventh day-removed all drainage and gave an intra-uterine douche of iodised solution. There was almost immediately a rise of temperature to $101^{\circ}$ and for 12 hours there was no discharge whatever. When the next douche was given the uterus was found once more to be filled with turbid, infective fluid. I therefore again inserted a glass drain and packed the vagina, and repeated this dressing on the following day. Discharge was now free and the temperature once more fell to normal. The patient's strength was, however, becoming exhausted and $I$ felt that if a repetition of the absurption from the uterus occurred great danger would be run. Fortunately I was given a free hand

1 The ecouvillon or mop is made of stout quill mounted on a wire stem. It thoroughly cleanses the uterine surface without the cutting effect of the steel instruments. It is readily sterilised by dry heat and is cheap, costing only $5 d$. They may be obtained at Messrs. Down Bros. or any Paris instrument maker. by both the patient and her family and I continued the drainage for six days, soon replacing the glass tube with diminishing amounts of iodoform gauze. The twice-daily douching and dressing were troublesome and trying to both my patient and to myself but we were rewarded by a persistently normal temperature and pulse, a gradually increasing strength and appetite, and a feeling of assurance that the danger was over.

The patient recovered with the same remarkable rapidity as that with which she fell ill and on the eighteenth day after ber confinement was able to be up. I may add that vaginal examination throughout detected no marked displacement of the uterus although the slight retroflexion present must have sufficed to kink the cervix and prevent the necessary discharge of lochia. Bacteriological examination of the fluid at the time of the curettage, on the eighth day, gave cultures of bacillus coli and micrococci of the tetrad group.

The interest of the case is great, for it is surely exceptional for the classical treatment of slight infection-namely, early curettage followed by intra-uterine douching-to fail. Not only did it fail but it seems morally certain, from the above record of the case, that it would have caused the patient's death or at any rate not prevented her death if persisted in.

In conclusion, if I may venture to point the moral, it is as follows: 1. Let the physician assure himself of the free flow of lochia in the days immediately following the confinement. Confidence in the assurance of the nurse upon this point may afterwards be regretted. 2. Drainage of the uterus, being simple, painless, and free from danger, should be practised early in certain cases.

Paris.

\section{A CASE OF CIRRHOSIS OF THE LIVER IN WHICH CURE OF THE ASCITES FOLLOWED AN OPERATION FOR THE RELIEF OF STRANGU- LATED UMBILICAL HERNIA.}

BY JOHN CLAY, M.B., B S. DURH., F.R C.S. ENG., ASSISTANT SURGEOY TO THE ROYAL VICTORIA INFIRMARY, NEWCASTLFON-TYNE; DEMONSTRATOR OF ANATOMY IN THE UNIVERSITY OF DURHAM.

ON Dec. 18th, 1906 I was asked by Dr. G. Armstrong Atkinson to see a patient who was suffering from strangulated umbilical hernia. The history of the patient, a man, aged 60 years, was that for four years he had suffered from ascites due to cirrhosis of the liver and during the latter part of the period the condition had become complicated by a hernia at the umbilicus. As so often happens in these cases, the present attack began very gradually with symptoms of obstruction of the lumen of the bowel, and it was only during the last day that signs of strangulation of the vessels supply. ing its walls appeared. On the night on which I saw the man he was very ill and as evidence of the strangulation a basin containing rather more than a pint of fæcal vomit was shown to me. There appeared to be little hope of a successful result for operation but none at all if affairs were allowed to take their course. The copious fæcal vomit absclutely contra-indicated a general anæsthetic, so I determined to relieve the condition, using a local anæsthetic only. $\beta$-eucaine was employed, about three grain boiled in one ounce of water with a little common salt. After cleaning the skin the neck of the sac was clearly exposed and the peritoneal cavity was opened immediately above it. From the peritoneal cavity the finger was passed into the sac which was then laid open together with its numerous ramifications, and the strangulation which was in one of them was relieved. The gut where strangulated was almost gangrenous, though recovery did not seem impossible. During the operation large quantities of ascitic flaid escaped. The bowel was returned to the abdominal cavity and the wound was sutured longitudinally in the usual way.

The patient, though somewhat wayward, made an excellent recovery and his medical attendant tells me to-day that he is better than he has been for some years and that no ascitic fluid has re-collected. The local anæsthetic acted well and no pain was felt in making the skin incision, bat the parietal peritoneum was extremely tender, considerably adding to the 